\title{
Tour Trends in Academic ARL Libraries
}

\section{Lori Oling and Michelle Mach}

\begin{abstract}
This study explores tour trends in academic Association of Research Libraries (ARL), specifically examining the prevalence of several tour formats, including guided, self-guided, and virtual Web tours. Results from a survey conducted in November 2000 include statistical information about tour administration, audience, and structure, as well as perceptions of librarians in the field. Although tours are still a standard service in most academic $A R L$ libraries, few libraries have formalized methods of testing the efficacy of each format. With the exception of guided tours, librarians' perceptions of tour effectiveness are dramatically inconsistent with the types of tours they choose to offer.
\end{abstract}

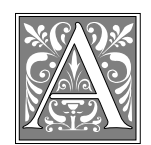

$t$ the beginning of fall semester, it is not unusual to see groups of freshmen guided through the labyrinth of the library by an enthusiastic professional. Students discover the plethora of services and resources available and leave the library eager to embark on their journey through the world of research.

Or not.

Although tours have long been a standard service in academic libraries, the idealistic scenario above is the often the exception rather than the rule. Regardless, many librarians feel that a comprehensive library tour is vital to the academic success of their students. Tours help students become oriented to the physical layout of the building, associate a friendly face with the library, and enable them to ask questions specific to their own needs. ${ }^{1-3}$ In contrast, other librarians question the value of tours. Tours do not give students hands-on research skills, nor do they engage the students' interest. ${ }^{4-6}$ In addition, the limited staffing at most libraries forces librarians to make difficult choices between offering tours or offering classroom instruction sessions, following a standardized script or creating a personalized tour and having librarian-guided tours or delegating the task to others. ${ }^{7-9}$

To address some of the negative aspects of tours, librarians have developed alternatives to the traditional guided tour such as self-guided, audiocassette, computerized, and Web tours. This study explores tour trends at academic Association of Research Libraries (ARL), specifically examining the prevalence of each tour format, administration, and audience.

\section{Literature Review}

The literature on library tours is somewhat elusive. One reason for this is that information about tours is often lumped

Lori Oling is Reference/Instruction Librarian at Colorado State University; e-mail: loling@manta.colostate.edu. Michelle Mach is Web Librarian at Colorado State University; e-mail: mmach@manta.colostate.edu. 
together with other library instruction components, instead of standing on its own. ${ }^{10}$ Another reason for the difficulty in identifying tour literature is the slippery terminology regarding tours. Some authors use the term library orientation to define a tour of the physical library building; others consider this a library tour. However, at other times, the terms library orientation and library tour are used to define a full-blown classroom instruction session. ${ }^{11}$

\section{This study of library tours examined the prevalence, administration, audience, structure, and evaluation of specific tour formats.}

The literature on library tours reflects the evolution of tour formats, from guided walking tours to today's virtual Web tours. Guided tours have long been a standard in academic libraries. ${ }^{12,13}$ Despite their prevalence, the perceived value of guided tours is mixed. Some feel that a guided tour is "critical in making an overwhelmed freshman more comfortable entering the library." ${ }^{\prime 14}$ Others question the value of the guided tour. As Barbara H. Phipps stated in 1968, "Chief objection to the tour seems to be that it usually comes before the student has a need to use the library and in the midst of much other orientation, rendering the student glassy-eyed and saturated with information and admonitions." 15

Although guided tours are still offered in today's academic library, other tour formats have come (and gone) over the past several decades, often reflecting the popular technology of the time. Most of these tour formats were created to compensate for perceived shortcomings of guided tours, such as intensive requirements for staffing and inefficient use of library instruction time. Self-guided tours with printed booklets gained popularity in the late sixties and early seventies. ${ }^{16}$ Formats that were popular in the 1970s but seem to be out of favor today include slide/tape programs and closed-circuit television. ${ }^{17,18}$ Videotape tours enjoyed a brief surge of popularity in the mid1980s. ${ }^{19}$

Although audiocassette tours were introduced in the 1970s, they became commonplace in the 1980s with the improved audiocassette technology and held steady well into the 1990s..$^{20-26}$ The wealth of literature on audiocassette tours paints a predominantly rosy picture of this tour format. Common positive factors mentioned include the self-paced aspect of audiocassette tours and the large numbers of students accommodated with minimal staff requirements. ${ }^{27,28}$ However, the student reaction to audiocassette tours appeared less positive. Students "found it to be only a moderately interesting experience" or were embarrassed to walk around the library carrying the audiocassette player. $^{29-31}$ Reports on the expense and ease of updating audiocassette tours were mixed. ${ }^{32-34}$

As personal computers became more common in libraries, new tour formats were developed using a variety of softwares, most notably HyperCard..$^{35-40}$ Like the audiocassette tour literature, there was initially a lot of enthusiasm for computerized tours. Most articles focused on the technical implementation of the tours rather than their effectiveness. ${ }^{41-44}$

And finally, as Internet use became more common and technology became more advanced in the mid-1990s, virtual Web tours were introduced..$^{45}$ However, little has been published on this relatively new tour format. As with earlier computerized tours, the focus of the literature thus far is on the technical implementation of the tour. ${ }^{46-50}$

The literature on tours often reflected practices in a single library and usually focused on a single format of tour. Some notable exceptions were studies done by Phipps, Lynch, Mensching, and Shirato and Badics. In 1965, Phipps analyzed the results of 126 surveys of colleges selected from American Universities and Colleges that indicated they offered some form of library instruction. ${ }^{51}$ Compared with other forms of library instruction, Phipps found that "the respondents to the ques- 
tionnaire rated the library tour the least effective, if used alone. Eighty-nine of the librarians $(56.7 \%)$, however, still use the library tour." ${ }^{52}$ In 1974, Mary Jo Lynch published the results of a survey that concentrated on library tours. ${ }^{53}$ These seventy-five libraries included those listed in Verna V. Melum's article, along with selected libraries from other sources. ${ }^{54}$ As the author herself admits, the study was not scientific. Rather than statistical data, Lynch related a variety of experiences and anecdotes.

For statistical research on library tours at a national level, LOEX has conducted three surveys in the past three decades. The original survey was done in 1979 by LOEX Director Carolyn Kirkendall. ${ }^{55}$ Using the same survey instrument in 1987, Teresa B. Mensching gathered comparative data on library instruction, including library tours. ${ }^{56}$ She surveyed more than 1,800 U.S. academic libraries and received 834 responses. Reflecting the popular technology available at the time of the survey, Mensching categorized library tours in the following ways: conducted, videotape, audiotape, slide/tape, and printed self-guides. In 1987, the three most popular types of tours were conducted $(86 \%)$, printed self-guides (32\%), and slide/tape (18\%). In the 1995 LOEX survey, Linda Shirato and Joseph Badics found that conducted ( $82 \%)$ and selfguided $(27 \%)$ tours were still the most heavily used formats, while videotape and slide/tape tours were declining. ${ }^{57}$ Recognizing that they were on the cusp of the Internet explosion, Shirato and Badics stated that "more changes might have been seen a year or two later because of the massive impact of the Web-but that will have to wait for another survey." 58

From the somewhat-dated literature and the disparity of librarian opinions regarding tour effectiveness, the present role of tours in academic libraries is unclear. Although the LOEX surveys provided some data on library tours, their focus was on library instruction, not library tours. Although the LOEX surveys give information on tour formats offered, there is no comparative information on staffing, attendance, and evaluation in the academic library environment. For instance, do factors such as student body population, size of library staff, or whether the institution is public or private impact the implementation of library tours? As the Internet makes remote access to the library more common, have library tour statistics been declining in the same way that circulation and reference statistics have? ${ }^{59}$ This study of library tours examined the prevalence, administration, audience, structure, and evaluation of specific tour formats. Perceptions of librarians on tour effectiveness and trends also were solicited.

\section{Methodology}

Because ARL libraries are a diverse group, including public and private libraries of different sizes geographically distributed throughout the United States and Canada, the authors of this study determined that they would provide a good cross section of data. The ARL Web site listed 121 libraries in November $2000 .{ }^{60}$ Of these, the authors limited their survey to the 111 academic libraries, eliminating ten public and special research libraries.

To answer the questions raised in the literature review, the authors designed a survey to gather information. The survey had eight sections and was intended to be anonymous. The first section profiled the library and the institution. Sections two through seven each focused on a specific format of tour: guided, self-guided, audiocassette, videotape, computerized, and virtual. Many of the sections asked similar questions to facilitate cross-comparisons. The final section sought librarian perceptions of tours in general and methods of user feedback. It also included the opportunity to provide open-ended comments.

The survey and a cover letter were sent in November 2000 with a return deadline approximately two weeks later. The survey was sent to instruction and reference librarians whose names were determined 
by looking at each library's Web site. If no name was listed, the information was requested from the library dean via email. After the first survey deadline, a postcard was sent to all survey recipients reminding them to return the survey. Out of 111 surveys, sixty-eight $(61 \%)$ were returned by the end of December 2000. One survey, received in February 2001, was not included in the final results because the data had already been tabulated.

\section{Results and Analysis}

\section{General Background: Institution profile}

To gather background information, the survey contained questions about institution type, student body size and distribution, and library staff size. Of the sixtyeight academic libraries responding to the survey, forty-nine identified themselves as public institutions, nineteen as private, and one library did not respond to the question. Surveys were received from institutions both large and small. The largest institution had a population of 50,000 students; the smallest had 4,300, with a mean of 24,545 . One person did not respond to the population question. Because the authors surmised that schools with largely undergraduate populations would be more likely to offer library tours, they asked for a breakdown of the undergraduate and graduate populations. Of the sixty-four libraries responding to this question, all institutions had both undergraduate and graduate populations. The undergraduate population ranged from 1,200 to 40,000 students, with a mean of 17,871 . The graduate population ranged from 500 to 28,522 students, with a mean of 6,283 .

Because tours can be labor-intensive, the authors felt that it was important to determine the staff size of the libraries responding to the survey. Of the fifty-nine libraries that responded to the question, the largest has 400 FTEs and the smallest has thirteen FTEs, with a mean of 145 . These numbers do not include branch libraries.

These institutional data were compared with the tour formats offered, as shown in figure 1. Regardless of the institution type, guided tours are by far the most popular, being offered by 93 percent of the libraries. Audiocassette, videotape, and computerized tours all scored less than four percent. For public institutions, self-guided tours were second most popular and virtual Web tours third. Private institutions reversed these positions, with Web tours being more popular than selfguided tours. Of the sixty-eight libraries that returned the survey, only two offer no tours at all.

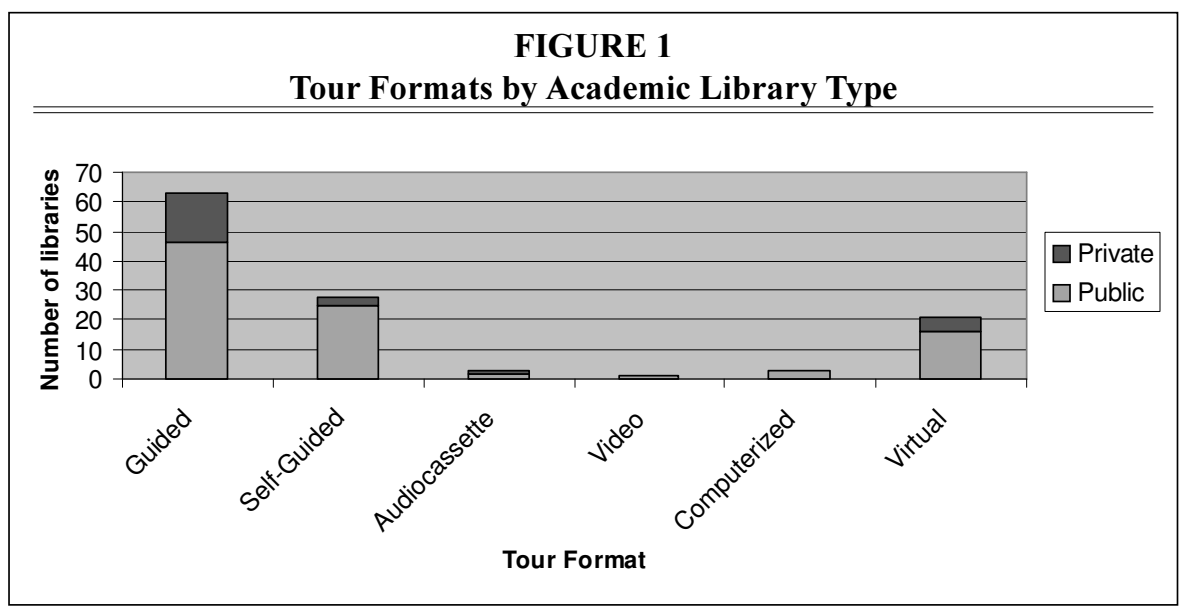




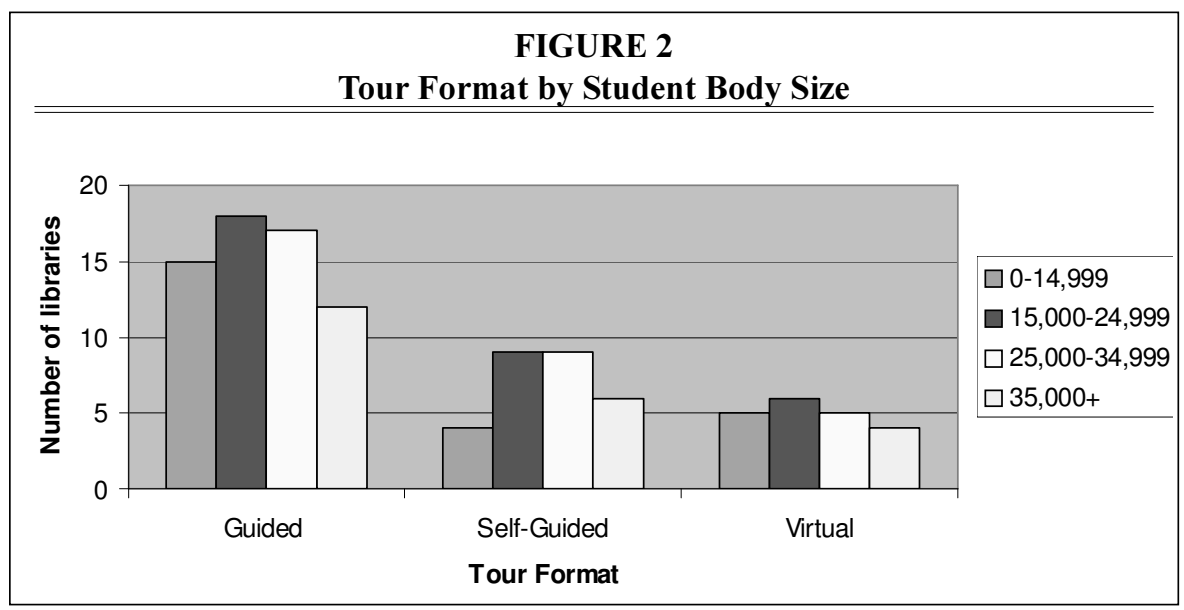

Not surprisingly, the same tours surfaced as the most popular when comparing the student body population or library staff size. In a few cases, the virtual tour eclipsed the self-guided tour for second place, as seen in figures 2 and 3. Student body sizes under 15,000 and libraries with staff sizes under 100 both favored the virtual Web tour over the self-guided tour.

\section{Guided Tours}

Guided tours, defined as a tours led by a trained person, were offered by sixtythree of the sixty-eight respondents. Libraries offered an average of ninety-three tours annually, with a median of sixty. Both the lowest number of tours offered (two) and the highest (400) were recorded by public institutions with stu- dent populations of between 25,000 and 35,000 .

Although 93 percent of the survey respondents offer guided tours, the comments regarding the effectiveness of guided tours were mixed. Some people felt that guided tours are an essential service provided by libraries, considering a spatial orientation to the library building as critical to student success. As one respondent wrote, "We believe in 'muscle memory,' actually walking through the physical building, not 'virtual' tours." On the other hand, some librarians were skeptical about the effectiveness of guided tours, especially with large groups. One person reported, "Traditional walkaround tours are completely ineffective with large groups and generally a waste

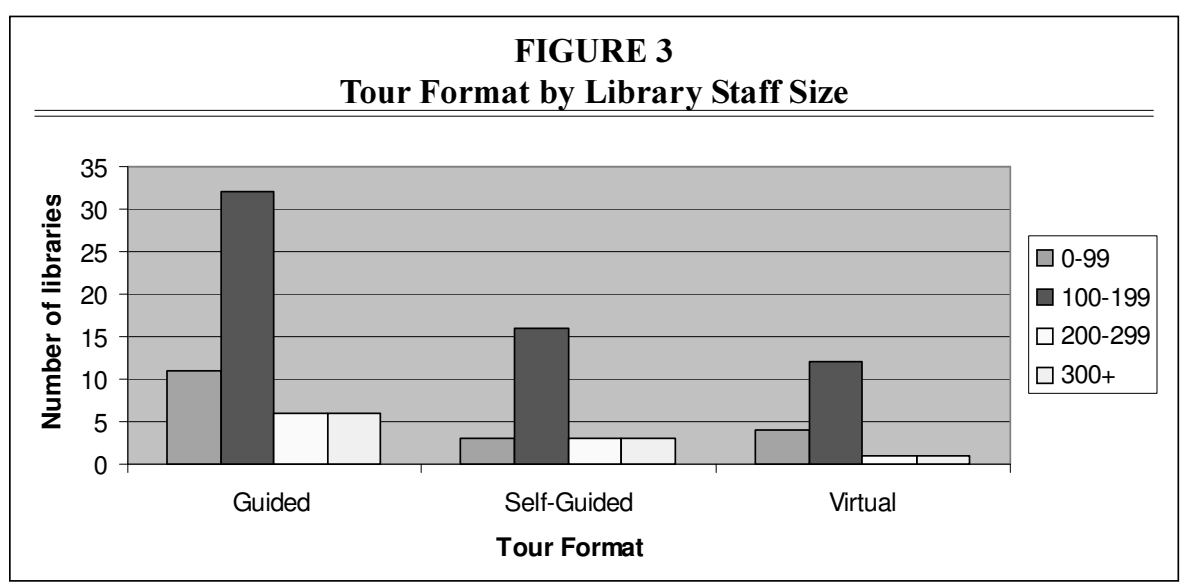


of time with small groups because folks are generally more comfortable asking for direction than they are on how to do research."

In addition to the number of tours offered, the authors were interested in administrative information about guided tours, such as how tours are staffed and updated, as well as specific details, such as scheduling, audience, and length. The question concerning administration of guided tours directed respondents to provide only one answer. Unfortunately, four respondents circled more than one answer, causing their answers for this question to be discarded. Of the fifty-nine remaining libraries, the reference or instruction units administer 85 percent of guided tours. Circulation, administration, and other units make up the remaining 15 percent.

Guided tours represent a significant time investment for libraries, with the majority (37\%) taking thirty-one to fortyfive minutes. Only 13 percent of libraries offer tours taking less than twenty minutes, and no libraries reported offering tours longer than one hour. The size of tour groups tended to be reasonable, with 38 percent reporting an average of six to ten attendees per group and 36 percent reporting an average of eleven to twenty attendees. No library reported a group larger than thirty people.

The majority of guided tours are led by librarians (94\%), staff $(67 \%)$, and students $(17 \%)$, with nonlibrary faculty such as instructors or teaching assistants, Friends of the Library, volunteers, and others making up less than 18 percent combined. (Percentages do not add up to $100 \%$ because respondents were asked to indicate all applicable answers.) Approximately twothirds of libraries follow a standard script that is updated every term or semester $(41 \%)$ or annually (37\%).

Guided tours are taken by a variety of people at ARL aca- demic libraries. To get an overall picture of everyone taking guided tours, respondents were directed to indicate all appropriate groups. Predictably, almost all libraries offered tours to freshmen, along with international students, transfer students, and graduate students (table 1). A group that was not listed on the survey but was repeatedly mentioned in the "other" category consisted of perspective students. Next, respondents were asked to rank the top three groups according to attendance. According to 63 percent, freshmen rank as the highest user group of guided tours, followed by graduate students (17\%) and international students $(12 \%)$.

In line with the traditional library service ethic, library tours were offered any time upon request by 70 percent of the responding libraries. Respondents also indicated that the first few weeks of a semester are a popular time for guided tours (67\%), which correlates with the high numbers of freshmen and transfer students taking the tours. Interestingly, only 63 percent reported that guided tours are part of a library instruction section. However, in a separate question, 93 percent of respondents answered that guided tours are sometimes part of a library instruction class. The reason for this discrepancy is unclear. Special events, such as parents' weekend and alumni weekend, were in-

TABLE 1
Libraries Offering Guided and Self-guided
Tours for Specific Groups

\begin{tabular}{lc} 
Groups & $\begin{array}{c}\text { Number of Libraries } \\
(\mathbf{n}=\mathbf{6 3})\end{array}$ \\
\hline Freshmen & 59 \\
International students & 55 \\
Transfer students & 52 \\
Graduate students & 51 \\
Sophomores/juniors/seniors & 46 \\
Special groups & 43 \\
K-12 students & 37 \\
Nonlibrary faculty and staff & 32 \\
General public & 20 \\
Other & 15 \\
\hline
\end{tabular}


dicated by 59 percent as common occasions for offering guided tours. Few libraries (21\%) scheduled guided tours regularly throughout the semester.

\section{Self-guided Tours}

Self-guided tours, defined as self-paced tours using booklets or printed information, were offered by twenty-eight of the sixty-eight respondents, making it the second most popular tour option. Many of the respondents commented that they have no way of tracking statistics on self-guided tours because there is little staff interaction with the tour takers. In addition, many libraries recycle their tour booklets, so counting booklets is not a viable option for collecting data. Only fourteen of twenty-eight respondents were able to provide statistical data on the average number of people taking self-guided tours. On average, 711 people take self-guided tours annually, with a median of 175. Although self-guided tours were sometimes used in library instruction classes, most respondents (68\%) never use them for that purpose.

Seventy-nine percent of reference or instruction units are primarily responsible for the content of the self-guided tour. Half of the respondents update the tour either every semester or annually; the remaining fourteen respondents update the tour content irregularly.

Popular locations for obtaining selfguided tour materials are the reference desk (57\%), a kiosk or display (57\%), and the information desk $(50 \%)$. Like the guided tour, the average length of selfguided tours was thirty-one to forty-five minutes, reported by 36 percent of the libraries. Self-guided tours tended to be shorter than guided tours, with 32 percent of the libraries reporting the average time to be less than twenty minutes and 25 percent reporting twenty-one to thirty minutes.

Seventy-five percent of libraries offer self-guided tours to freshmen and gradu- ate students, closely followed by international students and transfer students (table 2). After identifying the various groups taking self-guided tours, respondents were asked to rank the heaviest users. As with guided tours, freshmen were the heaviest users at most libraries. Surprisingly, the general public ranked third after transfer students.

\section{Audiocassette, Computerized, and \\ Videotape Tours}

The next three sections of questions dealt with audiocassette, computerized, and videotape tours. An audiocassette tour was defined as a tour on a portable audio player. A computerized tour was defined as a tour with limited access points, such as CD-ROM or HyperCard. A videotape tour was defined as a tour shown on videocassette. According to respondents, these were by far the least popular tour formats. Three libraries reported that they currently use audiocassette or computerized tours; only one library uses videocassette tours. Comments indicated that these tour formats are no longer used because they are time-consuming to create, costly to update, and seldom used by patrons.

\section{Virtual Web Tours}

Virtual Web tours, defined as tours available on the Web, were offered by twentyone of the sixty-eight respondents, making it the third most popular tour option. 
Four additional respondents reported that virtual Web tours are under construction at their libraries. Only seven of twenty-one respondents were able to provide statistical data on the average number of people taking virtual tours. On average, 1,855 people take virtual tours annually, with a median of 500 .

Virtual tours were used in library instruction classes more often than selfguided tours, with 57 percent of respondents sometimes incorporating them into their classes. One possible reason that virtual tours are used in library instruction classes is their short duration. Fifty-two percent reported that virtual tours take less than ten minutes. Only 14 percent reported that the tours take longer than twenty minutes, and no libraries reported virtual tours longer than thirty minutes. In addition to being used in instruction, one respondent also noted that Web tours are particularly useful for "visiting groups who want some background information before they come."

As with the guided and self-guided tours, almost all the virtual tours (86\%) are the responsibility of the reference and instruction units. Most of the respondents $(57 \%)$ update the tour either every semester or annually, with most of the remaining respondents (38\%) updating its content irregularly. Common features of the virtual tour include text descriptions $(90 \%)$, maps $(86 \%)$, and photographs $(81 \%)$. Panoramas, sound, and videos/ movies are rarely used.

\section{Perceptions}

In addition to the statistical data, the authors were interested in the perceptions of professionals working in the field. Sixty-three librarians responded to this section of the survey. Considering that the majority of libraries offered guided tours, it was predictable that 82 percent of the librarians felt that guided tours were the most effective tour medium. It appears to be all or nothing when it comes to library tours; after guided tours, the next most popular response was that tours are not effective $(8 \%)$. As stated by one respon- dent, "Tours have a limited impact-better to have staff available for one-on-one interaction." Although the statistical data showed that self-guided tours were the second most prevalent tour format offered, only seven percent of librarians found them to be most effective. Audiocassette tours and virtual Web tours tied at two percent of librarians finding them to be the most effective tour medium, which is notable because virtual Web tours were used by 31 percent of respondents and audiocassette tours were used by only 4 percent.

Although most listed guided tours as being the most effective tour medium, this question provoked a large number of comments. One respondent spoke for many, stating, "This depends on what you're trying to achieve. What's the assignment? Who's the audience? There are too many variables to say definitively which is the most effective. Of course, it's great to have a guided tour conducted by trained staff, but patrons may not want to come to the library in person, but still need the information, so a Web/vtour may be best."

Forty-two percent of librarians ranked staffing as the most important factor in deciding what type of tour to offer. Requests from teaching faculty $(17 \%)$ and students/users (13\%) also were important factors. Other factors suggested by librarians included effectiveness, pedagogy, public relations, and previous tour attendance.

Although 97 percent of the libraries offer tours, few actively solicit user feedback. Of the libraries that responded to this section, 65 percent do not solicit any feedback. Of the libraries that do request feedback, most use surveys or questionnaires $(21 \%)$ whereas a few use focus groups or anecdotal feedback. According to one respondent, "When one gives a live tour, one can judge how the participants are getting the material. Other times, when tours are part of classes, evaluations are passed out and collected with questions about the usefulness of the tour portion." 
Most libraries (38\%) reported that the number of requests for tours in 1998-2000 stayed the same. A significant number of libraries (32\%) reported that requests for tours were decreasing. Only a fifth (22\%) of the libraries reported an increase in the number of tour requests.

\section{Discussion}

After examining the data from the survey, several interesting points surfaced. As found in the literature review, some people answering the survey also pointed out the linguistic confusion over the word tour. Many classroom instructors call to request a tour but, in actuality, are expecting their students to learn about library catalogs and databases, which are best taught in a classroom. Although librarians tend to differentiate between tour and instruction session, many classroom faculty do not. According to one respondent, 'Our classes were called 'tours,' so the whole concept of doing away with these things has been hard for some folks to grasp." As pointed out by another respondent, "As such, the tours themselves are not really the object of demand, but certainly attendance at 'stand alone' tours has dropped off ... while demand for library instruction, with and without tours, has steadily increased."

A surprising point that appeared to contradict the findings in the literature review was the popularity of the guided tour. Despite the fact that 93 percent of libraries reported offering guided tours, few articles have focused on guided tours in the past two decades. In contrast, most articles on tours focus on the use of technology. However, this survey indicates that these tours are seen as a distant third option after guided and self-guided tours. Even virtual Web tours, the current technological favorite, were only used by 31 percent of the survey respondents.

Although most libraries tend to use multiple tour formats, few libraries have formalized methods for testing the efficacy of each format. With the exception of guided tours, librarians' perceptions of tour effectiveness are dramatically incon- sistent with the types of tours they choose to offer. This was especially apparent in the case of the virtual Web tour, where only two percent of librarians considered them to be the most effective tour medium, even though 31 percent of respondents offered them. More formalized user feedback on tour effectiveness would assist librarians in determining the appropriate tour formats to offer.

\section{Despite the infiltration of technol- ogy into all other areas of the library, the most popular tour continues to be the traditional guided tour.}

Staffing is another concern when choosing tour formats. Although many librarians listed staffing as a top deciding factor in tour decisions, most libraries continue to offer staff-intensive guided tours. Librarians themselves lead 94 percent of guided tours. Although it is commendable that librarians involve themselves to such an extent, it may be more pragmatic to explore other staffing options. Staffing is still an issue when creating, implementing, and updating other tour formats as well.

The survey findings indicate that the demand for library tours is not increasing at most academic libraries. One possible reason for this is that librarians are actively discouraging them. Many comments indicated that librarians view tours as ineffective if they do not accompany a library instruction session. "Tours without an instruction component are not encouraged. When we receive calls for tours, we are persuasive about instruction components, if appropriate," said one respondent. Another person wrote, "Over the past few years, we have been convincing faculty on campus that tours are of limited value when they occur independent of instruction sessions. This probably accounts for the decrease." Other speculative reasons for declining tour requests may be decreasing building use, advances in technology, or because tours are not meeting the needs of users. Future studies could verify this finding, explore the 
factors leading to this possible decline, and, if appropriate, determine whether this trend is acceptable to the profession.

\section{Conclusion}

This survey found that tours are still being offered in ARL academic libraries. Despite the infiltration of technology into all other areas of the library, the most popular tour continues to be the traditional guided tour. Whether a library is public or private, small or large, does not appear to affect this finding. Past trends show that tours relying on "modern" technology, such as slide/tape, videotape, audiocassette, and stand-alone computers, experienced only a brief surge of popularity before being replaced by something else. Unlike previous technologies, virtual Web tours allow remote access and an unlimited number of simultaneous users. Despite these advantages, it remains to be seen whether the virtual Web tour will outlast its tour ancestors and match the popularity of the old-fashioned guided tour.

\section{Notes}

1. Pixey Anne Mosley, "Assessing the Comfort Level Impact and Perceptual Value of Library Tours," Research Strategies 15 (winter 1997): 261-70.

2. Lucy M. Salmon, "Instruction in the Use of a College Library," in User Instruction in Academic Libraries: A Century of Selected Readings, comp. Larry L. Hardesty, John P. Schmitt, and John Mark Tucker (Metuchen, N.J.: Scarecrow Pr., 1986), 86-101.

3. Susan Gray Byrd, "We're Not 'Rounding Them Up' Anymore: The Self-guided Cassette Tape Library Tour at Miami-Dade," Community and Junior College Libraries 1, no. 2 (winter 1982): 59-69.

4. Ibid.

5. Colleen Boff, “Transforming Library Orientation Tours," LOEXNews 27, no. 3 (fall 2000): 5, 11.

6. Barbara H. Phipps, "Library Instruction for the Undergraduate," College \& Research Libraries 29 (Sept. 1968): 411-23.

7. Byrd, "We're Not 'Rounding Them Up' Anymore."

8. Candace R. Benefiel, "Planning and Testing a Self-guided Taped Tour in an Academic Library," RQ 29 (winter 1989): 199-207.

9. Boff, "Transforming Library Orientation Tours."

10. Mary Jo Lynch, "Library Tours: The First Step," in Educating the Library User, ed. John Lubans Jr. (New York: R. R. Bowker, 1974), 255.

11. James Rice Jr., Teaching Library Use: A Guide for Library Instruction (Westport, Conn.: Greenwood Pr., 1981), 46-61.

12. Lynch, "Library Tours," 257.

13. Salmon, "Instruction in the Use of a College Library." 261.

14. Mosley, "Assessing the Comfort Level Impact and Perceptual Value of Library Tours,"

15. Phipps, "Library Instruction for the Undergraduate," 413.

16. Lynch, "Library Tours," 259-62.

17. Ibid., 264-66.

18. Julia F. Baldwin, "The Comparative Effectiveness of a Slide/Tape Show and a Library Tour," College \& Research Libraries 40 (Jan. 1979): 31-35.

19. Teresa B. Mensching, "Trends in Bibliographic Instruction in the 1980s: A Comparison of Data from Two Surveys," Research Strategies 7, no. 1 (winter 1989): 8.

20. Lynch, "Library Tours," 262-64.

21. Gayle A. Poirier, "The Cassette Tour: An Effective, Efficient Orientation," Research Strategies 10 (summer 1992): 143-44.

22. Benefiel, "Planning and Testing a Self-guided Taped Tour in an Academic Library."

23. Charles Forrest and Mary Gassmann, "Development of a Self-guided, Audiocassette Tour at a Large Academic Library: Preliminary Report," Research Strategies 4 (summer 1986): 116-24.

24. Marilyn S. Hautala and Mary T. Mick, "University of Nebraska at Omaha Library Audio Tour," Nebraska Library Association Quarterly 22 (fall 1991): 42-45.

25. Lorna Peterson, "A Survey of U.S. Libraries on the Use of Audiotape Orientation Tours," Research Strategies 14 (winter 1996): 22-35. 
26. Byrd, "We're Not 'Rounding Them Up' Anymore."

27. Ibid.

28. Poirier, "The Cassette Tour."

29. Byrd, "We're Not 'Rounding Them Up' Anymore," 63.

30. Forrest and Gassmann, "Development of a Self-guided, Audiocassette Tour at a Large Academic Library," 122.

31. Benefiel, "Planning and Testing a Self-guided Taped Tour in an Academic Library," 203.

32. Ibid., 204.

33. Byrd, "We're Not 'Rounding Them Up' Anymore," 69.

34. Forrest and Gassmann, "Development of a Self-guided, Audiocassette Tour at a Large Academic Library," 123.

35. Dan Sienkiewicz, "A Sam Starr Mystery: Building a Computerized Tour for the Library," Medical Reference Services Quarterly 13 (winter 1994): 77-86.

36. Jill C. Harrell, "Converting Your Favorite Instructional HyperCard Designs to an IBM Environment," Library Software Review 13 (spring 1994): 27-34.

37. V. Lonnie Lawson, "Using a Computer-assisted Instruction Program to Replace the Traditional Library Tour: An Experimental Study," RQ 29 (fall 1989): 71-79.

38. _ , "A Cost Comparison between General Library Tours and Computer-assisted Instruction Programs," Research Strategies 8 (spring 1990): 66-73.

39. Sarah J. Vasse, "Creating 'MILT': A Multimedia Interactive Library Tour," in The Impact of Technology on Library Instruction, ed. Linda Shirato (Ann Arbor, Mich.: Pierian Pr., 1995), 233-35.

40. Jeff Chaffin, "Macintosh-assisted Library Orientation Tour," College and Research Libraries News 48 (June 1987): 332-34.

41. Ibid.

42. Vasse, "Creating 'MILT.",

43. Sienkiewicz, "A Sam Starr Mystery."

44. Harrell, "Converting Your Favorite Instructional HyperCard Designs to an IBM Environment."

45. Pixey Anne Mosley and Daniel Xiao, "Touring the Campus Library from the World Wide Web," Reference Services Review 24 (1996): 7-14.

46. Ibid.

47. Eloisa Gomez Borah, "A Virtual 'Hello': A Web-based Orientation to the Library," Journal of Business and Finance Librarianship 3 (1997): 3-18.

48. Linda Shirato and Joseph Badics, "Library Instruction in the 1990s: A Comparison with Trends in Two Earlier LOEX Surveys," Research Strategies 15 (winter 1997): 223-37.

49. Arthur Downing and Leo Robert Klein, "A Multilingual Virtual Tour for International Students," College E Research Library News 62 (May 2001): 500-502.

50. Daniel Yi Xiao, "Experiencing the Library in a Panorama Virtual Reality Environment," Library Hi Tech 18, no. 2 (2000): 177-84.

51. Phipps, "Library Instruction for the Undergraduate."

52. Ibid., 413.

53. Lynch, "Library Tours."

54. Verna V. Melum, "1971 Survey of Library Orientation and Instruction Programs," Drexel Library Quarterly 7 no. 3\&4 (1971): 225-52.

55. Carolyn Kirkendall, "Library User Education: Current Practices and Trends," Library Trends 29 (summer 1980): 29-37.

56. Mensching, "Trends in Bibliographic Instruction in the 1980s."

57. Shirato and Badics, "Library Instruction in the 1990s," 230.

58. Ibid., 223.

59. Martha Kyrillidou, "Research Library Trends: ARL Statistics," Journal of Academic Librarianship 26 (Nov. 2000): 433.

60. See http://www.arl.org/members.html. 